UDC $630^{*} 81$

\title{
PHYSICO-CHEMICAL PARAMETERS OF SIBERIAN LARCH (LARIX SIBIRICA) BARK EXTRACTED WITH WATER-AMINO-ALCOHOLIC EXTRACTANTS
}

\author{
(c) \\ E.A. Petrunina*, O.A. Shapchenkova, S.R. Loskutov \\ V.N. Sukachev Institute of Forest, Russian Academy of Sciences, \\ Akademgorodok, 50/28, Krasnoyarsk, 660036 (Russia), \\ e-mail: petrunina@ksc.krasn.ru
}

This paper presents the results of a thermal analysis, that involved thermogravimetry (TG/DTG) and differential scanning calorimetry (DSC), of natural bark of Siberian larch (Larix sibirica Ldb.) vs. the bark extracted with $5 \%$ water-monoethanolamine (MEA) and (vs.) 5\% water-triethanolamine (TEA). Thermogravimetric data obtained in an oxidative (air) atmosphere allowed us to identify temperature ranges of thermal decomposition stages for the larch bark samples, as well as to determine the corresponding mass loss and mass loss rate at programmed heating. The Ozawa-Flynn-Wall (OFW) method was used to calculate the dependence of activation energy of the thermal decomposition of experimental samples on the conversion degree $\left(E_{a}=f(\alpha)\right)$; the symbate run of $E_{a}=f(\alpha)$ curves was established. The DSC data obtained agreed with those of TG/DTG. The integral heat of the bark thermal decomposition $(9.60 \mathrm{~kJ} / \mathrm{g}$ and $14.12 \mathrm{~kJ} / \mathrm{g}$ for MEA and TEA, respectively) indicated the bark to be competitive with other biofuels, such as briquetted lignin, wood pellets, sunflower husk, rapeseeds, and straw. calorimetry.

Keywords: Siberian larch bark extracted with water-amino-alcoholic extractants, thermogravimetry, differential scanning

\section{Introduction}

Bark, tons of which become a wood-processing waste at large timber mills, was and still is of scientific interest regarding ecological safety and, more important, sustainable natural resource use. Over a few of years, we have conducted studies on the extraction of Siberian larch bark with water-organic extractants, modification of the bark to obtain a cation exchange sorbent, as well as development of an absorbent for mineral oils and hydrocarbon oils [1-8]. Thermal properties of the bark are still little studied, whereas these properties are critical regarding the possibility to use the bark as a filler of building blocks, thermal stability of which is crucially important. Moreover, bark, after it was modified or extracted, is necessary to be utilized and a promising utilization would be to briquette the bark or to combine it with crop-processing waste in pellets.

Thermal analysis enables to estimate influence of different treatments on the plant material by the mass loss at the thermal decomposition (degradation) stages, each stage temperature interval, the rate of thermal decomposition, and the value of thermal effects occurring within the temperature range of interest [9]. The kinetic analysis of thermogravimetric data [10-14] makes it possible to precisely differentiate samples with respect to the activation energy at individual stages of thermal decomposition for subsequent development of methods (technologies) of final utilization of plant materials under study $[12,13,15,16]$. The major bark components are hemicellulose, cellulose, lignin and a wide variety of extractives, diversity and contents of which are usually higher than in wood and depend on woody species. The proportions and chemical composition of these components determine TG, DTG, and DSC

Petrunina Elena Alexandrovna - engineer, e-mail: petrunina@ksc.krasn.ru

Shapchenkova Olga Aleksandrovna - Cand. Sci. (Biology), Senior Scientist, e-mail: sholga@ksc.krasn.ru

Loskutov Sergey Redzhinaldovich - Dr. Sci. (Chemistry),

Fellow of the IAWS, e-mail: 1sr@ksc.krasn.ru curve shapes, kinetic parameters of conversion, and, at large, the "thermal portraits" of the samples of interest.

The main stages, the thermal effects, and kinetics of nonisothermal thermo-oxidative degradation of bark and its components of different woody species in

\footnotetext{
${ }^{*}$ Corresponding author.
} 
TG and DSC experiments have been described in a number of studies $[9,14,16,19,20]$. Our analysis of literature lead us to the general conclusion that, based on TG/DTG and DSC parameters and kinetics of thermal decomposition of natural and modified bark samples, it is possible to differentiate samples by their belonging to particular wood species and by the influence of processing methods in order to determine the directions of further use.

The objective of this study was to compare the thermal decomposition of Siberian larch (Larix sibirica Ldb.) natural bark with that of the bark extracted with 5\% water-monoethanolamine (MEA) and $5 \%$ water-triethanolamine (TEA).

\section{Materials and methods}

We sampled bark of Siberian larch trees of age classes II and III growing in Krasnoyarsk forest-steppe zone. Large bark pieces, after air-drying at a room temperature of $21 \pm 2{ }^{\circ} \mathrm{C}$, were chopped and $0.5-1.0 \mathrm{~mm}$ fraction was separated for using in the experiments to follow. The procedure of bark extraction with water-amino-alcoholic extractants and chemical (group) composition of extracts are described in works [4, 7].

TG and DSC were performed using, respectively, TG 209 F1 and DSC 204 F1 devices (NETZSCH, Germany). Bark samples were analyzed in an air atmosphere. For TG, they were heated from $25^{\circ} \mathrm{C}$ to $700{ }^{\circ} \mathrm{C}$ at 10,20 , and $40{ }^{\circ} \mathrm{C} \cdot \mathrm{min}^{-1}$ heating rates in a cylindrical corundum crucible, with gas flow of $20 \mathrm{ml} \cdot \mathrm{min}^{-1}$ and sample (particles of $\sim 0.5 \mathrm{~mm}$ ) mass ranging 7.37 to $9.75 \mathrm{mg}$. For DSC, samples were heated from $25{ }^{\circ} \mathrm{C}$ to $590{ }^{\circ} \mathrm{C}$ at $10{ }^{\circ} \mathrm{C} \cdot \mathrm{min}^{-1}$ heating rate in an aluminum crucible with a perforated lid (an empty aluminum crucible taken as standard), with gas flow of $40 \mathrm{ml} \cdot \mathrm{min}^{-1}$ and sample mass ranging 0.24 to $1.24 \mathrm{mg}$. To calibrate the devices, we used the standard substances that came with the devices. All TG/DTG and DSC measurements were made using "averaged" samples. The standard deviation of mass loss at different stages of thermal degradation varied from 0.21 to $1.07 \%$, the temperature of the maximum DTG - from 0.36 to $0.84{ }^{\circ} \mathrm{C}$; $\mathrm{DTG}_{\max }$ - from 0.08 to $0.68 \% \cdot \mathrm{min}^{-1}(\mathrm{P}=0.05)$. The differences in sample thermal degradation parameters that exceeded the experimentally determined measurement error were believed to be reliable.

Below, we will use the following abbreviations: NLB for natural larch bark, LB (MEA) for larch bark extracted using water-monoethanolamine extractant with $5 \%$ of MEA, and LB (TEA) for larch bark extracted using water-triethanolamine extractant with $5 \%$ of TEA.

To analyze sample thermal degradation kinetics, we applied Ozawa-Flinn-Wall (OFW) isoconversion method $[17,18]$ to the TG data obtained. OFW method is widely used to calculate kinetical characteristics of thermal degradation of various materials based on TG curve analysis [10-14]. According to OFW theory [16], activation energy equation is [21]:

$$
\ln (\beta)=\ln \left(\frac{A E_{\alpha}}{R F(\alpha)}\right)-5.3305-1.052 \frac{E_{\alpha}}{R T},
$$

where $\alpha$ is the degree of conversion $\left(\alpha=\left(\mathrm{m}_{0}-\mathrm{m}\right) /\left(\mathrm{m}_{0}-\mathrm{m}_{\mathrm{f}}\right)\right) ; m_{0}$ is the initial mass of sample subjected to TG; $m$ is the current sample mass at temperature $T ; m_{f}$ is the final sample mass after thermal degradation; $F(\alpha)$ function is mathematical representation of the kinetic model. The activation energy of the thermal degradation of a sample is determined by inclination of line built in $\ln \beta-1 / \mathrm{T}$ coordinates for a number of $\alpha$ values and to know the reaction mechanism (order) is not required.

\section{Results and discussion}

DTG curves for the experimental samples are given in Fig.1. Applying NETZSCH Proteus Thermal Analysis 4.8.4 program package enabled to identify inflections and maximums, based on which we determined temperature ranges and their corresponding mass losses on TG curves (fig. 2).

Mass loss of NLB, LB (MEA) and LB (TEA) samples in the temperature range $170-360{ }^{\circ} \mathrm{C}$, where the thermal decomposition of carbohydrate (hemicellulose and cellulose) complex and condensed tannin mainly occurs, varied considerably by number of "fractions" and relative percent of each fraction (fig. 2). A similar picture was observed for $370-560{ }^{\circ} \mathrm{C}$ range, where mainly polyphenols degrade. 
Fig. 1. DTG curves of NLB (1), LB (MEA) (2), and LB (TEA) (3) thermal decomposition at a heating rate of $10^{\circ} \mathrm{C} \cdot \mathrm{min}^{-1}$ in an air atmosphere
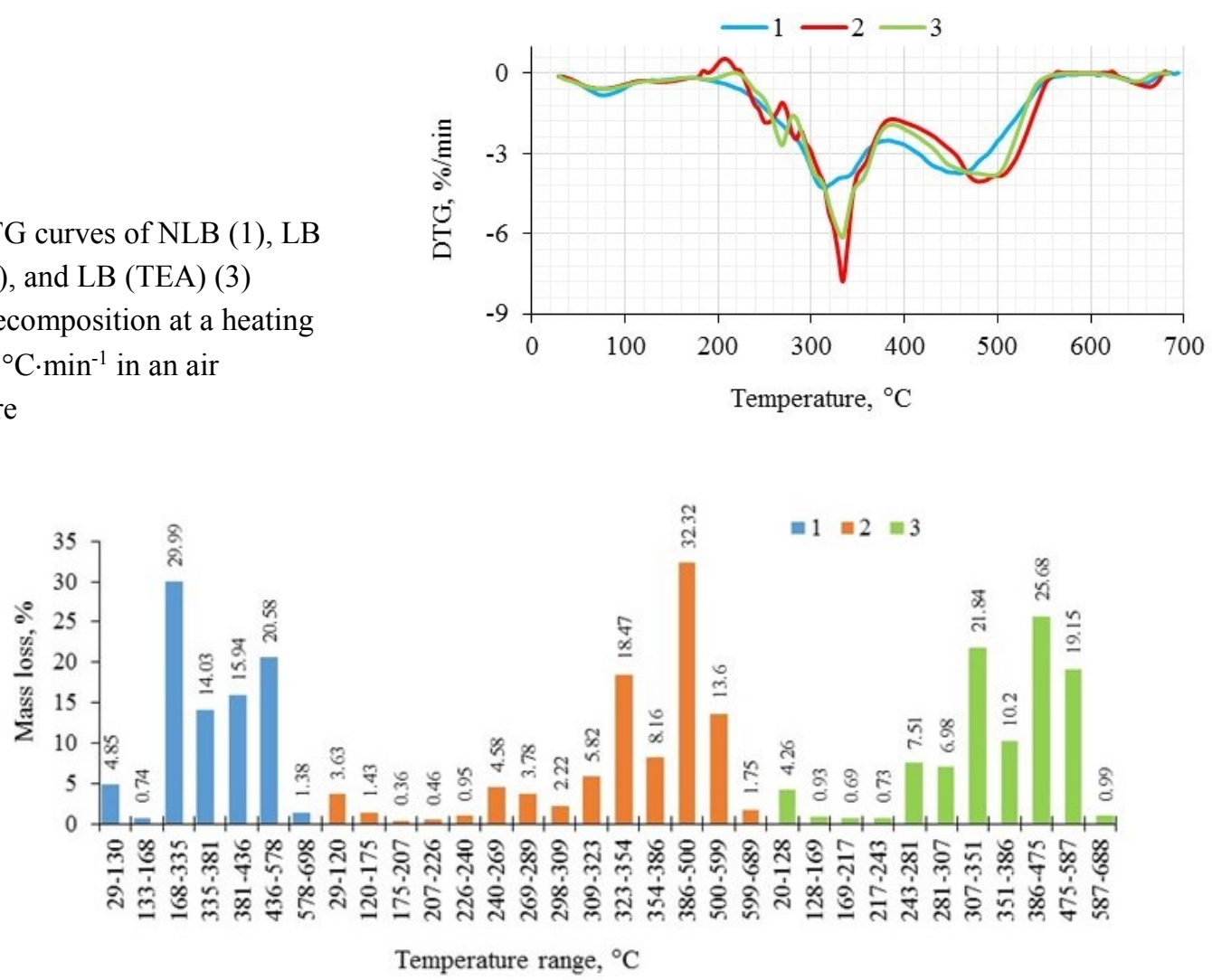

Fig. 2. The mass loss of NLB (1), LB (MEA) (2), and LB (TAE) (3) at a heating rate of $10^{\circ} \mathrm{C} \cdot \mathrm{min}^{-1}$ in an air atmosphere

DTG curve shape, peak temperature, and the maximum mass loss rate of carbohydrate and aromatic components of bark changed considerably after extractives were removed (fig. 1). The temperature of peak related to the decomposition of LB (MEA) and LB (TEA) carbohydrate complex increased by $30{ }^{\circ} \mathrm{C}$ and the maximum mass loss rate was higher 1.7 and 1.4 times, respectively, compared to NLB (fig. 1). Unlike in NLB, the peak temperature of thermal degradation of LB (MEA) and LB (TEA) polyphenol complex was higher by $25^{\circ} \mathrm{C}$ and $40{ }^{\circ} \mathrm{C}$, respectively, with DTG amplitude remaining practically the same. For the final stage of thermo-oxidative degradation (620$690{ }^{\circ} \mathrm{C}$ ) of coal formed at previous stages we determined the following values of DTG parameters: peak temperature of $659{ }^{\circ} \mathrm{C}, 664{ }^{\circ} \mathrm{C}$, and $649{ }^{\circ} \mathrm{C}$ and $\mathrm{DTG}_{\max }$ of $0.37 \% \cdot \mathrm{min}^{-1}, 0.51 \% \cdot \mathrm{min}^{-1}$, and $0.30 \% \cdot \mathrm{min}^{-1}$ for NLB, LB (MEA), and LB (TEA), respectively. Our results are in agreement with the observations of Poletto et al. (2010) and Shangguan et al. (2018) who reported that water-soluble compounds influenced on the thermal degradation of wood (Pinus taeda, Eucalyptus grandis) and cork (Quercus variabilis).

The variation of TG curve shape among samples is clear from the plots in fig. 3. Four temperature subranges were found $\left(20-399^{\circ} \mathrm{C}, 399-409^{\circ} \mathrm{C}, 409-519^{\circ} \mathrm{C}\right.$, and $\left.519-700{ }^{\circ} \mathrm{C}\right)$, within which sample thermal stability changed.

Fig. 4 shows LB (MEA) and LB (TEA) plots based on OFW equation. Fig. 5 demonstrates dependence of the activation energy on the conversion degree.

The plots of dependence of the activation energy on the conversion degree occurred at various "heights" relative to X-axis (fig. 4). However, all $E_{a}=f(\alpha)$ curves had two segments with maximum $E_{a}$ within $0.1-0.5$ and 0.5-0.9 conversion degree intervals, where thermal decomposition of carbohydrates and aromatic compounds mainly occurred, respectively. The significant changes of dependence $E_{a}=f(\alpha)$ found for LB (MAE) and LB (TEA) were obviously due to the extraction and indicated that the thermal stability of bark changed considerably.

The DSC curves obtained for larch bark samples are shown in fig. 6. Extraction of bark with water-aminoalcoholic extractants resulted in considerable changes of its thermal decomposition parameters: temperature of DSC curve maximums and their corresponding values of heat flow. Cumulative thermal effects of $15.54 \mathrm{~kJ} / \mathrm{g}$ for NLB, $9.60 \mathrm{~kJ} / \mathrm{g}$ for LB (MEA), and $14.12 \mathrm{~kJ} / \mathrm{g}$ for LB (TEA) indicated that extraction affected the thermal decomposition of larch bark. When determining the exothermic effect of thermo-oxidative decomposition of bark in a bomb calorimeter, the result usually exceeds the DSC data by $15-20 \%$. 


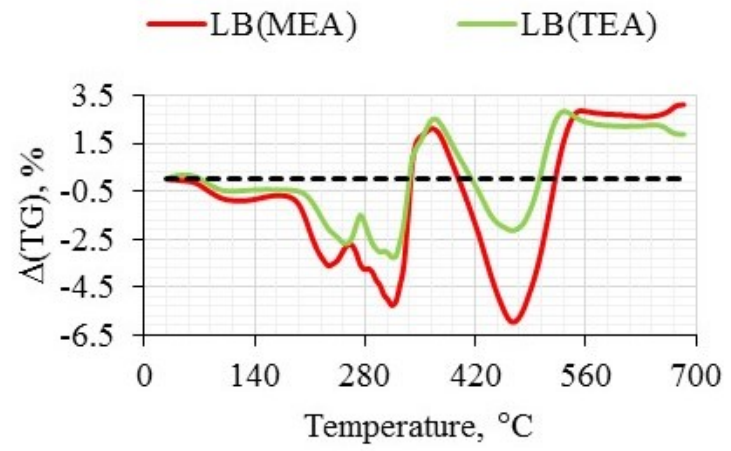

Fig. 3. Advance (curves located above dashed line) and lag (curves located below dashed line) of mass loss of bark after extraction compared to natural bark represented as the difference between mass loss of NLB and mass loss of LB (MEA), LB (TEA) at a heating rate of $10^{\circ} \mathrm{C} \cdot \mathrm{min}^{-1}$ in an air atmosphere
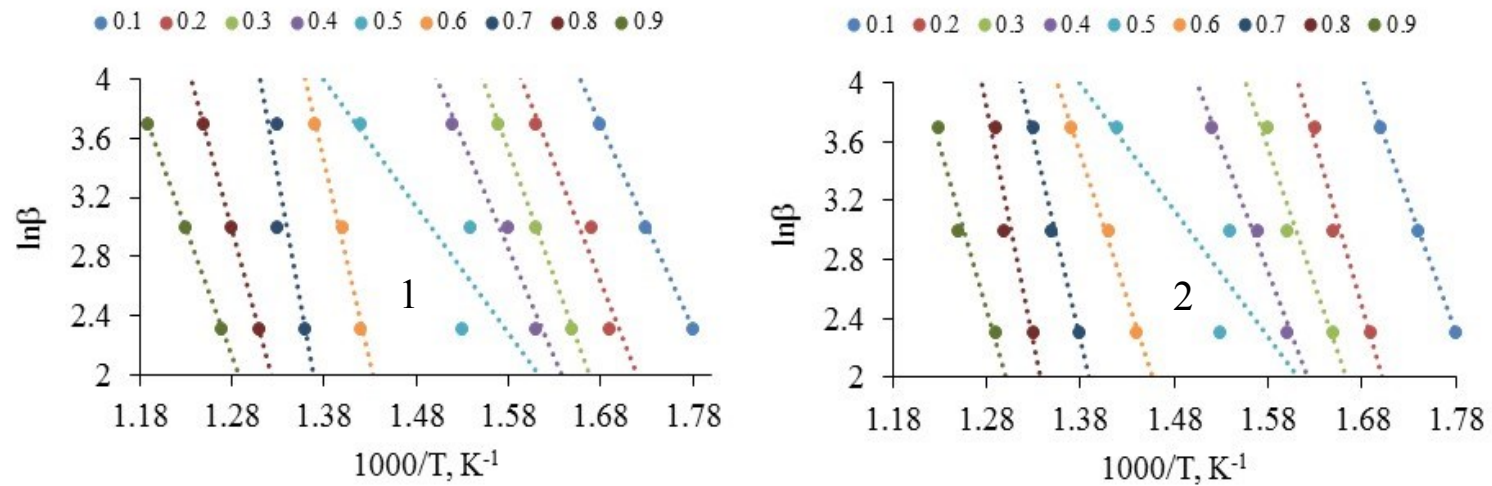

Fig. 4. OFW-based plots of LB (MEA) (1) and LB (TEA) (2) for given conversion values

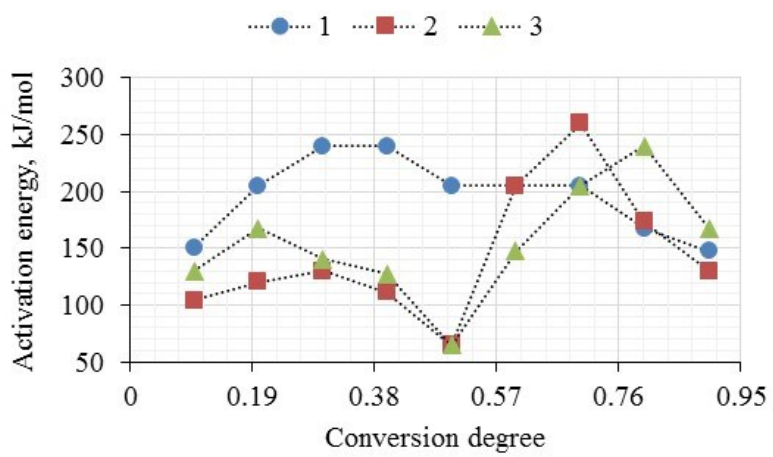

Fig. 5. Dependence of the activation energy on the conversion degree for NLB (1), LB (MEA) (2), and LB (TEA) (3)

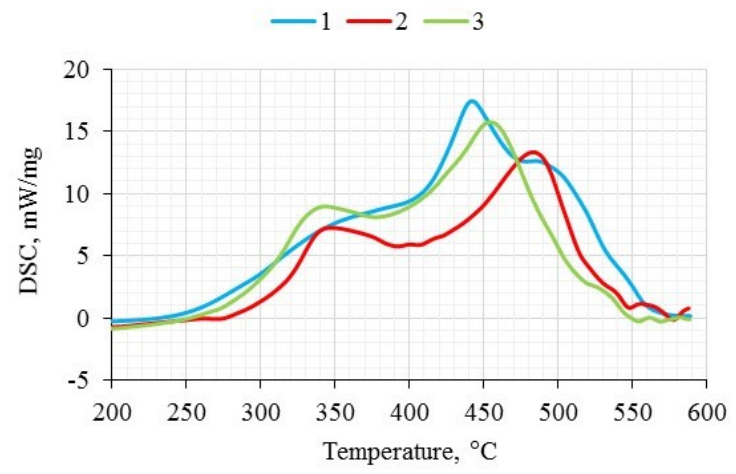

Fig. 6. DSC curves of NLB (1), LB (MEA) (2), and LB (TEA) (3) at a heating rate of $10^{\circ} \mathrm{C} \cdot \mathrm{min}^{-1}$ in an air atmosphere

\section{Conclusion}

Removal of substances with aqueous-amino-alcoholic extractants from Siberian larch bark led to a significant change of its thermal decomposition parameters determined by thermogravimetry, differential scanning calorimetry and kinetic analysis of thermogravimetric data.

In the temperature range of preferential decomposition of hemicelluloses, the "multistep" mass loss was observed. The larch bark extracted with MEA or TEA was characterized by a smaller mass loss when heated to 280 $310^{\circ} \mathrm{C}$ and higher thermal stability at temperature above $400{ }^{\circ} \mathrm{C}$ compared to natural larch bark. This allows us to consider larch bark extracted with MEA and TEA as an environmentally friendly insulating material or as an insulating component. 
The integral exothermic effects of thermal decomposition of natural larch bark and larch bark extracted with TEA ( 15.54 and $14.12 \mathrm{~kJ} / \mathrm{g}$ ) determined by DSC indicate that these materials are promising both as biofuels and as a part of fuel compositions.

\section{References}

1. Loskutov S.R., Permyakova G.V., Aniskina A.A., Peryshkina G.I. Rastitelnye resursy, 1997, vol. 33, no. 2, pp. 74-78. (in Russ.).

2. Permyakova G.V., Loskutov S.R., Semenovich A.V. Khimija Rastitel'nogo Syr'ja, 2008, no. 2, pp. 43-46. (in Russ.).

3. Loskutov S.R., Semenovich A.V., Permyakova G.V. Khimija Rastitel'nogo Syr'ja, 2008, no. 2, pp. 113-117. (in Russ.).

4. Loskutov S.R., Semenovich A.V., Aniskina A.A., Permyakova G.V., Plyashechnik M.A. Produkty tekhnicheskogo naznacheniya iz kory khvoynykh porod. [Technical products from coniferous bark]. Novosibirsk, 2010, 113 p. (in Russ.).

5. Semenovich A.V., Loskutov S.R. Khimija Rastitel'nogo Syr'ja, 2015, no. 4, pp. 101-109. (in Russ.).

6. Semenovich A.V., Shapchenkova O.A., Aniskina A.A., Loskutov S.R. Journal bulletin of ASAU, 2016, vol. 14, no. 1, pp. 76-81.

7. Patent 2678683 (RU). 2019. (in Russ.).

8. Loskutov S.R., Petrunina E.A., Shapchenkova O.A., Plyashechnik M.A., Stasova V.V. Lesnoy vestnik, 2020, no. 2, pp. 98-110. (in Russ.).

9. Dulman V., Odochian L., Dumitras M., Cucuman S. J. Serb. Chem. Soc., 2005, vol. 70, no. 11, pp. 1325-1333. DOI: 10.2298/JSC0511325D.

10. Shen D.K., Gua S., Luo K.H., Bridgwater A.V., Fang M.X. Fuel, 2009, vol. 88, pp. 1024-1030. DOI: 10.1016/j.fuel.2008.10.034.

11. Cruz G., Crnkovic P.M. J. Therm. Anal. Calorim., 2016, vol. 123, pp. 1003-1011. DOI: 10.1007/s10973-015-4908-2.

12. Loskutov S.R., Shapchenkova O.A., Aniskina A.A. Sibirsky Lesnoy Zhurnal, 2015, no. 6, pp. 17-30. (in Russ.).

13. Tyutkova E.A., Loskutov S.R., Shashkin A.V., Benkova V.E. J. Therm. Anal. Calorim., 2017, vol. 130, pp. $1391-1397$. DOI: $10.1007 / \mathrm{s} 10973-017-6550-7$.

14. Shangguan W., Chen Z., Zhao J., Song X. Wood Sci. Technol., 2018, vol. 52, pp. 181-192. DOI: 10.1007/s00226-0170959-9.

15. Broido A.A. J. Polym. Sci. Part A-2., 1969, vol. 7, no. 10, pp. 1761-1773. DOI: 10.1002/pol.1969.160071012.

16. Ozawa T.A. Chem. Soc. Jpn., 1965, vol. 38, no. 11, pp. 1881-1886. DOI: 10.1246/bcsj.38.1881.

17. Poletto M., Dettenborn J., Pistor V., Zeni M., Zattera F.J. Materials Research, 2010, vol. 13, no. 3, pp. 375-379. DOI: 10.1590/S1516-14392010000300016.

18. Haykiri-Acma H., Yaman S. World Renewable Energy Congress. Bioenergy Technology. Linkoping, 2011, pp. 251257. DOI: 10.2495/WM120141.

19. Fang P., McGinnis G.D., Parish E.J. Wood and Fiber, 1975, vol. 7, no. 2, pp. 136-145.

20. Gaugler M., Grigsby W.J. Journal of Wood Chemistry and Technology, 2009, vol. 29, no. 4, pp. 305-321. DOI: 10.1080/02773810903165671.

21. Mamleev V., Dourbigot S., Le Bras M., Lefebvre J. J. Therm. Anal. Calorim., 2004, vol. 78, pp. 1009-1027.

Received August 26, 2020

Revised March 10, 2021

Accepted March 12, 2021

For citing: Petrunina E.A., Shapchenkova O.A., Loskutov S.R. Khimiya Rastitel'nogo Syr'ya, 2021, no. 2, pp. $103-107$. (in Russ.). DOI: $10.14258 /$ jcprm.2021028340. 
